\title{
Partial reward and positive contrast effects*
}

\author{
ROBERT LEHR \\ State University of New York, Cortland, New York 13045
}

\begin{abstract}
In two experiments, groups of rats were given $50 \%$ or $100 \%$ of either a large (eight pellets) or small (one pellet) reward. All rats were then given 100\% large reward. A 20-sec delay of reward was used throughout. Positive contrast effects were obtained in both experiments and schedule of reward did not interact with this effect.
\end{abstract}

The negative contrast effect (NCE) of magnitude of reward (Ss exposed to large then small rewards run slower than Ss exposed to only small reward) has been fairly widely reported. However, positive contrast effects (PCE) (Ss exposed to a small reward run faster to a large reward than Ss exposed to only the large reward) have been more elusive and, until recently, have rarely been reported (see Dunham, 1968).

Shanab, Sanders, and Premack (1969) reported what appeared to be PCEs when they introduced a delay of reward in the shift phase. Following Shanab et al, Mellgren (1971, 1972) found that delay of reward throughout training resulted in PCEs. Mellgren (1971) gave rats small or large rewards at a constant $20-\mathrm{sec}$ delay. After various amounts of training, all rats were given the large reward at the same $20-\mathrm{sec}$ delay. He reported PCEs in each comparison. One of Mellgren's explanations for obtaining the PCE was that his procedures allowed the PCE to be demonstrated. He suggested that when immediate reward is used, there may be a "ceiling" effect (Bower, 1961). The large reward Ss may be running as fast as possible, and the shifted Ss simply cannot run any faster. The procedure that Mellgren used (delay) resulted in generally slower running for all Ss, which allows room for the PCE to be demonstrated.

The NCE has been widely reported (Dunham, 1968). However, Mikulka, Lehr, and Pavlik (1967) found that partial reward (PR) during the preshift phase considerably reduced, if not eliminated, the NCE. They explained their results in terms of frustration theory, but the results are also explainable by most theories of the effects of PR on extinction (Amsel, 1958; Capaldi, 1966; Capaldi \& Ziff, 1969). That is, the small reward can be considered to be similar to the nonreward of extinction. The PR Ss are more persistent in the face of disruptive stimuli (nonreward in extinction or small reward in the shift studies) and are, thus, slower in their change in behavior. In the shift study the result was that

*The author thanks M. B. King for the rats and G. Sumperer and $D$. Novick for assistance in running the $S$ s. Preparation of this article was completed while the author was a visiting scholar at the University of Utah. Reprints may be obtained from the author at the Department of Psychology, State University of New York, Cortland, New York 13045. the NCE was not observed or was greatly delayed (Bohmer \& Ison, 1966; Capaldi \& Ziff, 1969; Mikulka et al, 1967).

The present report investigated the effect of schedules of reward on the PCE. Rats were given a small reward on either a PR or continuous (CRF) schedule and were then shifted to large reward CRF. In terms of incentive shifts, it might be predicted that the PR Ss have a greater shift in incentive and, as a result, the possibility of obtaining the PCE should be enhanced. As a control for the shift in schedules, a large reward PR group was included. This group was shifted from large reward $P R$ to large reward CRF to assess the effects of shifting schedules per se. No clear predictions can be made of the differential effects of PR on upward reward shifts. However, the data may help to clarify some of the effects of PR on responding in general.

\section{EXPERIMENT I}

\section{Method}

Subjects. The Ss were 28 male hooded rats raised in the Cortland laboratory and derived from the Syracuse University strain. The rats were 75 to 84 days old at the start of acquisition. All rats had been screened for mouse killing but were naive with respect to the present procedures and apparatus.

Apparatus. The runway used was painted flat black and was $2.44 \mathrm{~m}$ long and $.13 \mathrm{~m}$ wide and high. The first $.30 \mathrm{~m}$ and the last $.46 \mathrm{~m}$ were separated from the alley by guillotine doors and constituted the start- and goalboxes, respectively. The startbox (SB) and goalbox (GB) were covered with hinged clear Plexiglas. The alley was covered with hardware cloth. Start, run, and goal times were recorded with .01-sec clocks and photoelectric relays from the opening of the start door over the first $.15 \mathrm{~m}$, the next $1.37 \mathrm{~m}$, and the next $.46 \mathrm{~m}$, respectively. A Davis pellet dispenser was hooked directly to the foodcup and was set to deliver the $.045 \mathrm{-g}$ Noyes pellet used as reward at a rate of $2 / \mathrm{sec}$ When the last photobeam was broken, an interval timer timed $20 \mathrm{sec}$ and then activated a stepper which controlled the number of pellets delivered. All of the apparatus was in the experimental room.

Design and Procedure. The experiment was a 2 by 2 factorial design with acquisition reward schedule (CRF or PR) and acquisition magnitude of reward (one or eight pellets) as factors. All rats were treated the same in the shift phase (eight pellets, CRF). Seven days before the start of acquisition all rats were placed on a food-deprivation schedule which consisted of approximately $12 \mathrm{~g}$ of Purina Lab Chow each day. Supplemental Noyes pellets were given in the home cage during training so that 
all rats received the same total amount of food each day. Pretraining consisted of 5 days of handling and 2 days of magazine training. The magazine training involved four direct placements into the GB for each rat on each of the 2 days before the start of acquisition training. The rats were assigned to squads of four, with one rat from each group in each squad. In magazine training a squad was taken to the experimental room in holding cages. The first rat was taken from the holding cage and placed directly into the GB as far as possible from the foodcup. This action broke the last photobeam and started the 20-sec delay interval. At the end of the delay, either one or eight pellets (depending on the group) was delivered. When the rat had consumed the pellets or after $1 \mathrm{~min}$, it was removed from the GB and placed in the holding cage. The next rat was then placed into the GB. When all the rats in a squad had finished the first placement, the first rat then received his second placement. All trials ended in the reward magnitude (one or eight pellets) appropriate to the rats' assigned group and all placements were rewarded. The order of running within a squad was fixed but was unsystematically determined for each squad. Acquisition training, which began the day after the second placement day, consisted of four trials each day for 8 days ( 32 trials). The procedures were essentially the same as for magazine training. The rat was placed into the SB and $2 \mathrm{sec}$ later the SB door was opened and the rat was allowed to traverse the alley. When the last photobeam was broken and the timing sequence described above began, the GB door was lowered to prevent retrace. As in pretraining, all rats in a squad had one trial before any had the next trial. The intertrial interval was 4-5 $\mathrm{min}$. For the CRF rats all trials were rewarded, while for the PR rats 16 of the 32 acquisition trials were rewarded. The reward schedule for the PR rats was as follows: $+00+, 0+0+,+0+0,0++0,00++, 0+0+,++00$, $+00+(+=$ reward, $0=$ nonreward $)$. On nonreward trials the timing sequence was the same as on reward trials, but the feeder never operated and the rat was confined for $10 \mathrm{sec}$ after the 20 -sec delay.

Starting on the day after acquisition, all rats received four large reward (eight pellets) trials on each of 7 days (28 trials). The procedures were the same as in acquisition, except that all the rats received CRF large reward.

\section{Results}

In addition to start, run, and goal times, total time was created by adding these three measures on each trial. Each time measure was converted to a speed score by a reciprocal transformation (one/latency). The daily average of these reciprocals was used for all analyses.

Acquisition. A 2 by 2 by 8 mixed analysis of variance was performed for each speed measure and included

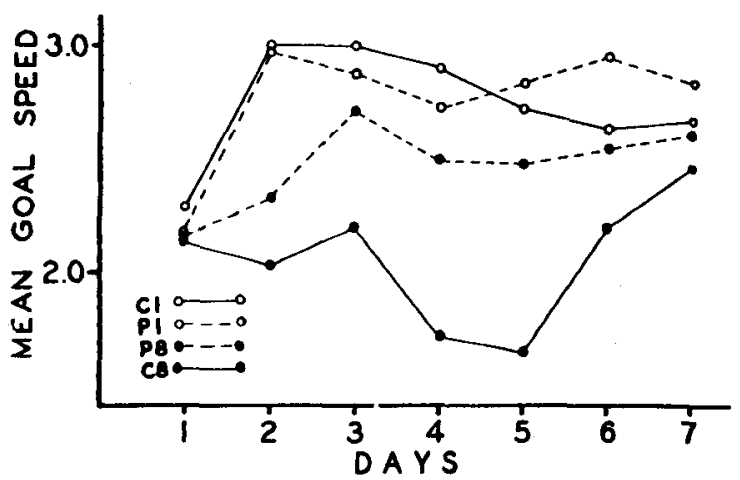

Fig. 1. Mean goal speed during shift phase in Experiment $I$. The group designations refer to the acquisition conditions, which were either one or eight pellets on a continuous (C) or partial (P) schedule. schedule of reward (PR or CRF), magnitude of reward (one or eight pellets), and acquisition days as factors. In addition to significant days effects in each measure (acquisition), the magnitude of reward effect was significant in start speed $[F(1,24)=8.28, p<.05]$, goal speed $[F(1,24)=4.49, p<.05]$, and total speed $[F(1,24)=4.68, p<.05]$. Large reward groups ran faster than small reward groups. No other effects were reliable.

Shift. In order to closely track the performance of the groups, each shift day was separately analyzed. A 2 by 2 factorial analysis was performed on each speed measure on each day of shift.

On Days 2, 3, 4, and 5, there were significant magnitude of reward effects in goal speed $[\mathrm{F}(1,24)=$ $19.68,5.52,8.21,8.84$, respectively, $\mathrm{p}<.05$ ] and total speed $[\mathrm{F}(1,24)=12.39,4.26,7.81,5.56$, respectively, $\mathrm{p}<.05]$. As can be seen in Fig. 1, the small reward groups ran faster than the large reward groups (a PCE). Similar effects were obtained in start and run speeds, but they were in general not statistically reliable. In run speed there was a magnitude of reward effect on Day 2 $[F(1,24)=7.57, p<.05]$ and a similar effect that approached significance on Day $3 \quad[F(1,24)=3.74$, $\mathrm{p}<.10]$. There were no other significant effects in any of the analyses.

There were no significant interactions between schedules and magnitude of reward in the shift phase. However, since individual group differences are of interest, post hoc tests were performed (Duncan's test, Edwards, 1972). In goal speed (Fig. 1) on Day 2, the CRF/one-pellet (C1) and PR/one-pellet (P1) groups were significantly different from the PR/eight-pellet (P8) and CRF/eight-pellet (C8) groups $(p<.05)$. On Day 3 adjacent groups did not differ, but both $\mathrm{C} 1$ and $\mathrm{P} 1$ were different from C8. On Days 4 and 5 Group C8 slowed down and was significantly $(p<.05)$ slower than the other groups, which did not differ. In total speed on Day 2, the group means were ordered P1, C1, P8, C8. Adjacent groups did not differ, and Group P1 was faster than P8 and $\mathrm{C} 1$ was faster than $\mathrm{C} 8(\mathrm{p}<.05)$. On Days 4 and 5 the groups were ordered as on Day 2, and adjacent groups did not differ. On Day $4 \mathrm{C} 1$ and $\mathrm{P} 1$ were faster than $\mathrm{C} 8$, while on Day 5 only $\mathrm{C} 1$ was faster than $\mathrm{C} 8$ $(p<.05)$. The picture that emerges from these analyses is similar to that shown in Fig. 1. Groups $\mathrm{C} 1$ and P1 never differed from each other and both ran faster than their appropriate control groups (Day 2, goal and total). In goal speed on Days 4 and 5 , when the C8 group slowed down, Group P8 was also faster than C8. This difference was not found in total speed.

\section{EXPERIMENT II}

Experiment II was run to test the reliability of the effects observed in Experiment I. The design was the same, but there were more trials in acquisition and extinction was run after the shift phase. 


\section{Method}

Subjects and Apparatus. The Ss were 24 male and 24 female 74- to 92-day-old rats of the same description as in Experiment I. The apparatus was the same as in Experiment I.

Procedure. The procedure was basically the same as in Experiment 1, with the following additions and exceptions: There were 14 days of acquisition (56 trials), 8 days of shift ( 32 trials), and 4 days of extinction (6 trials each day, 24 total trials); each squad was all male or all female; the females received $10 \mathrm{~g}$ as their basic ration; the schedule of reward was $+00+$, $0+0+,+0+0,0++0,00++, 0+0+,++00,+00+, 0+0+,+0+0,0++0$, $00++, 0+0+,++00$; in extinction all trials for all rats were the same as nonreward trials in acquisition.

\section{Results}

Time data were converted to speeds and averaged as in Experiment I. The extinction averages were based on six trials rather than four trials.

Acquisition. A 2 by 2 by 14 mixed analysis of variance was performed for each speed measure and included schedules of reward, magnitude of reward, and acquisition days as factors. In addition to significant days effects in each speed measure, in run speed there was a significant magnitude of . reward effect $[F(1,44)=14.65, \quad p<.05]$ and a Magnitude by Schedules interaction $[F(1,44)=4.39, p<.05]$. The large reward rats ran faster than the small reward rats, and this effect was bigger for the PR groups than for the CRF groups. There was also a significant interaction between days and schedules of reward $[F(13,572)=$ $2.05, \mathrm{p}<.05]$. A plot of this interaction shows that the PR groups ran slightly faster than the CRF groups in the middle of training but slower than the CRF groups on days toward the end of training. In total speed there were significant effects of magnitude of reward $[F(1,44)=4.71, p<.05]$ and the interaction of Schedule of Reward by Days $[F(13,572)=2.25$, $\mathrm{p}<.05]$. These effects were similar to the run speed effects. There were no other significant effects.

Shift. Each shift day was analyzed as in Experiment I. There were no significant effects in start speed. In run speed (see Fig. 2) there were significant effects of magnitude of reward on Days 2, 3, 4, and $5[F(1,44)=$ $4.42,6.00,6.05,6.04$, respectively, $\mathrm{p}<.05]$. The small reward groups ran faster than the large reward groups (a PCE), and there was no interaction between schedules and magnitude of reward. Duncan's tests on run speed showed that adjacent groups did not differ and that P1 was significantly $(\mathrm{p}<.05)$ faster than $\mathrm{C} 8$ on Days 2,3 , 4 , and 5 (Fig. 2). Group $\mathrm{C} 1$ also ran faster than C8 on Days 3 and 4 . In goal speed there was a significant schedules effect on Day $1[\mathrm{~F}(1,44)=5.53, \mathrm{p}<.05]$, representing faster speeds for the PR groups. In total speed the interaction of Schedules by Magnitude of Reward on Day 4 was significant $[F(1,44)=5.32$, $p<.05]$. The order of the group means from fastest to slowest was $\mathrm{C} 1, \mathrm{P} 8, \mathrm{P} 1, \mathrm{C} 8$. The only significant difference was between the $\mathrm{C} 1$ and $\mathrm{C} 8$ groups (Duncan's test). There were no other reliable effects in any shift speed measure. In Experiment I the PCE was shown most reliably in goal speed and to a lesser extent in run

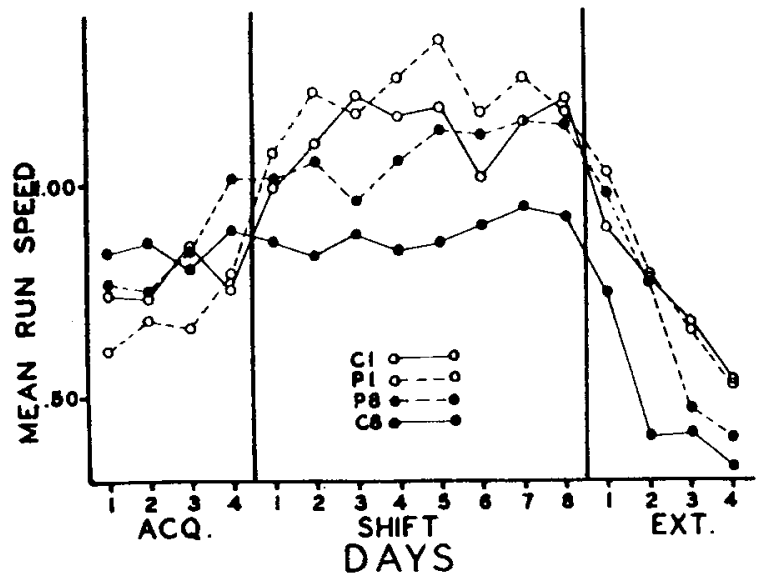

Fig. 2. Mean run speed for the last 4 days of acquisition, the 8 days of shift, and the 4 days of extinction in Experiment II.

speed. In Experiment II the major effect was in run speed. In both experiments the shift curves for all speeds were remarkably similar to those shown in Figs. 1 and 2 .

Extinction. The daily average reciprocal for each speed measure was used for analysis (six trials each day). In each speed measure there were significant effects of days, which show that the rats got slower across days (extinction). The only other significant effect was a magnitude of reward effect in run speed $[F(1,44)=7.26, p<.05]$, which represented faster running by the small reward groups. The expected partial reinforcement extinction effect (PR groups extinguishing slower than CRF groups) approached reliability in goal speed $[F(1,44)=3.16, p<.10]$, but in no other speed.

\section{DISCUSSION}

The present results show that the PCE can be reliably obtained when delay of reward is used throughout training. This is consistent with Mellgren's previous reports. When CRF is used, the PCE and NCE seem to be similar. Mellgren (1972) found both PCE and NCE using the delay procedure used here. Therefore, the delay itself does not seem to interfere with either type of contrast effect.

Interest in PCEs has been to some extent generated by the failure to obtain PCEs using procedures that reliably produce NCEs. This has resulted in theoretical interpretations that stress the differences between upward and downward shifts in magnitude of reward (Spence, 1956; Capaldi \& Lynch, 1967). For example, the NCE can fairly easily be explained by frustration that results from the downward shift in reward. The observation that the NCE occurs and then disappears with continued training is consistent with the frustration explanation (Mikulka et al, 1967). However, the similar findings with the PCE (Mellgren, 1972; present data) cannot be so easily explained. Frustration theory cannot explain PCEs or their disappearance. Adaptation level theory (Helson, 1964; Bevin \& Adamson, 1960) seems to fit the present data better and can explain both PCEs 
and NCEs in the same terms. Shanab and Biller (1972), however, found that neither an absolute nor a relative explanation of the effects of reinforcement could explain all of their shift findings. More research on the parameters of the delay and magnitude of reward will be necessary before an explanation can emerge. However, the reliability of the PCE using a between-Ss design is no longer in doubt.

The effect of PR on contrast effects seems to depend on the direction of the shift in rewards. Shifts downward are slowed down after PR (Bohmer \& Ison, 1966; Capaldi \& Ziff, 1969; Mikulka et al, 1967), while shifts upward are at least not slowed down (Hulse, 1962; present data). The failure obtain any interaction between schedules and magnitude of reward suggests that when the situation is made "better," PR may be understood in terms of incentive effects. That is, the PR groups may be averaging rewards (Logan, 1960; Peters \& $\mathrm{McHose}, 1974$ ) such that the effective reward in the preshift is smaller than for the CRF groups. This would result in a greater incentive shift for the PR groups. The P8 group was included to control for just this type of effect, and the P8 group did run slightly faster than the C8 group in both experiments. Leung and Jensen (1968) found overshooting in a group shifted from CRF to PR with a one-pellet reward and 150 acquisition trials. Possibly. with more training a similar effect would occur using the present procedures. It should be noted that the effects of schedule shifts are not at all consistent. Shifts from CRF to PR have resulted in decreases in speeds (Mikulka et al, 1967), increases in speeds (Badia, 1965), and essentially no changes in speeds (Leung \& Jensen, 1968; Rashotte, Adelman, \& Dove, 1972). More research on the parameters of both the schedules and magnitudes of rewards will be needed before a clear picture of the effects of schedule shifts can emerge.

\section{REFERENCES}

Amsel, A. The role of frustrative nonreward in noncontinuous reward situations. Psychological Bulletin, 1958, 55, 102-119.
Badia, $P$. Effects of drive, reinforcement schedule, and change of schedule on performance. Journal of Experimental Psychology, 1965, 69, 292-297.

Bevan, W., \& Adamson, R, R einforcers and reinforcement: Their relation to maze performance. Journal of Experimental Psychology, 1960, 59, 226-232.

Bohmer, H. M., \& Ison, J. R. The effects of reward magnitude changes following partial reinforcement. Paper presented at the meeting of the Midwestern Psychological Association, Chicago, May 1966.

Bower. G. H. A contrast effect in differential conditioning. Journal of Experimental Psychology, 1961, 62, 196-199.

Capaldi, E. J. Partial reinforcement: An hypothesis of sequential effects. Psychological Review, 1966, 73, 459-477.

Capaldi, E. J., \& Lynch, D. Repeated shifts in reward magnitude: Evidence in favor of an associational and absolute (noncontextual) interpretation. Journal of Experimental Psychology, 1967, 75, 226-235.

Capaldi, E. J., \& Ziff, D. R. Schedule of partial reward and the negative contrast effect. Journal of Comparative \& Physiological Psychology, 1969, 68, 593-596.

Dunham, P. J. Contrast conditions of reinforcement: A selective critique. Psychological Bulletin, 1968, 69, 295-315.

Edwards, A. L. Experimental design in psychological research. New York: Holt, R inehart, and Winston, 1972.

Helson, H. Adaptation-level theory: An experimental and systematic approach to behavior. New York: Harper and Row, 1964.

Hulse, S. H. Partial reinforcement, continuous reinforcement, and reinforcement shift effects. Journal of Experimental Psychology, 1962, 64, 451-459.

Leung, C. M., \& Jensen, G. D. Shifts in percentage of reinforcement viewed as a change in incentive. Journal of Experimental Psychology, 1968, 76, 291-296.

Logan, F. A. Incentive. New Haven: Yale University Press, 1960.

Mellgren, R. L. Positive contrast in the rat as a function of number of preshift trials in the runway. Journal of Comparative \& Physiological Psychology, 1971, 77, 329-336.

Mellgren, $R$. L. Positive and negative contrast effects using delayed reinforcement. Learning \& Motivation, 1972, 3, 185-193.

Mikulka, P. J., Lehr, P., \& Pavlik, W. B. Effect of reinforcement schedules on reward shifts. Journal of Experimental Psychology, 1967, 74, 57-61.

Peters, D. P.. \& McHose, J. H. Effects of varied preshift reward magnitude on successive negative contrast effects in rats. Journal of Comparative \& Physiological Psychology, 1974, 86, 85-95.

Rashotte, M. E., Adelman, L., \& Dove, L. D. Influence of percentage reinforcement on runway running in rats. Learning \& Motivation, 1972, 3, 194-208.

Shanab, M. E., \& Biller, J. D. Positive contrast in the runway obtained following a shift in both delay and magnitude of reward. Learning \& Motivation, 1972, 3, 179-184.

Shanab, M. E., Sanders, R., \& Premack, D. Positive contrast in the runway obtained following a shift in both delay and magnitude of reward. Science, 1969, 164, 724-725.

Spence, K. W. Behavior theory and conditioning. New Haven: Yale University Press, 1956.

(Received for publication January 10, 1974; accepted A pril 22, 1974.) 